\title{
A relação estabelecidos-outsiders na teoria de Norbert Elias: considerações acerca do caráter processual das sociedades, da formação da auto-imagem e do equilíbrio de poder.
}

\author{
Fernando Kulaitis ${ }^{1}$
}

\begin{abstract}
Norbert Elias (1897-1990) é um autor que incomoda aqueles preocupados com a sociologia e com as disciplinas que com ela se identificam, como é o caso da história. A sua obra é, muitas vezes, considerada simplesmente de caráter histórico. Porém, Elias realiza suas análises através de uma perspectiva sociológica processual, desenvolvendo e aplicando um arcabouço teórico e metodológico que nos leva a repensar os conceitos e categorias de análise sociológica que se concretizaram ao longo do tempo. Sua preocupação perpassa por diferentes abordagens em relação ao desenvolvimento teórico da sociologia, à pesquisa empírica e em sua capacidade de abordagem perante a realidade. Muito pode ser estudado e escrito sobre Norbert Elias e sua obra, que não é detalhista mas é rica em detalhes. Porém aqui, interessa apresentar a construção que faz da chamada relação estabelecidos-outsiders, destacando nela outros elementos importantes da sua sociologia.
\end{abstract}

Estabelecidos e outsiders não são grupos de pessoas pólos em uma relação. São grupos de pessoas interdependentes. A palavra estabelecidos vem do inglês establishment e established. Elas indicam um grupo que se enxerga e é enxergado pelos outros como a "boa sociedade", trazendo consigo a idéia de melhor, de mais prestígio e poder. A "boa sociedade" indica a auto-imagem de um grupo, estabelecida principalmente em relação a outro. Essa é uma das considerações norteadoras de uma relação estabelecidos-outsiders: a de que um establishment só se verifica quando em relação aos outsiders. Estes, de certa forma, são aqueles que estão fora da "boa sociedade". A heterogeneidade é maior e os laços pelos quais se unem são mais frouxos. (ELIAS, 2000, p. 7)

A relação estabelecidos-outsiders, como modelo teórico, é tão geral em sua aplicação que pode ser considerada, por exemplo, na análise da tradição das uniões familiares comunitárias que compartilham códigos de conduta bastante coesos em relação a outro grupo, como também na história dos conflitos étnicos ocorridos nos Estados Unidos da América, ou ainda nas representações de uma sociedade de corte, em que os rituais e etiquetas que

\footnotetext{
'Graduação - Ciências Sociais/UFPR. 
processavam o cotidiano dos cortesãos eram mais valorizados do que a riqueza financeira da burguesia ${ }^{2}$, entre muitas outras possíveis.

As diferenças entre esses grupos não se verificam necessariamente pela classe social, etnia, educação ou outra categoria de classificação. Eis aqui um ponto que transcende os paradigmas acadêmicos estabelecidos. É de acordo com uma configuração específica que se processa essa separação interdependente. Ao trazer a noção de interdependência, presente ao longo de suas obras, Elias pretende substituir a visão da sociedade concebida como algo exterior e para além dos indivíduos. Falar de interdependência indica a noção de que as pessoas estão unidas de diferentes formas pois estão direcionadas umas para as outras. (ELIAS, 1999, p. 15) Em outras palavras, o que Elias demonstra é que as pessoas formam teias de interdependência e configurações de diferentes formas conforme processos a longo prazo. Assim, desde um âmbito mais particular, como a família, até o âmbito das cidades e dos estadosnação, podem ser considerados como configurações ou teias de interdependência, retirando-lhes uma característica simplesmente política, cultural, social ou histórica e colocando as relações que acontecem entre essas características numa análise que envolve os processos a que estão submetidas. Então, até mesmo a divisão clássica entre "sociedade" e "indivíduo" não aparece, nessa perspectiva, como entes separados em que aquele exerce coerção sobre este e em que a "sociedade" figura acima dos indivíduos. Elias mostra que as forças sociais, ou que o equilíbrio de poder como algo estrutural nas relações humanas, são na verdade "forças exercidas pelas pessoas, sobre outras pessoas e sobre elas próprias.” (ELIAS, 1999, p.17)

Numa relação estabelecidos-outsiders, ambos os termos só são possíveis na relação que os separa e que os une, podendo-se destacar três abordagens principais: o caráter histórico-processual das configurações e formações que caracterizam um certo momento social, a formação da autoimagem e da imagem dos "outros" de um grupo em relação a outro e deste em relação aquele, o que de certa forma destaca-se na obra de Elias, e uma sociologia das formas de poder.

Deve-se ter cuidado com o conceito de poder. Na sociologia de Elias o poder não deve ser considerado em si, mas no equilíbrio em que se encontra a partir da interdependência entre pessoas e grupos de pessoas. Ou seja, Elias considera que o equilíbrio de poder é um elemento fundamental das relações humanas, sendo no mínimo bipolar. (ELIAS, 1999, p. 80-81) A idéia de

\footnotetext{
${ }^{2}$ A questão étnica nos EUA é tratada por Elias através da análise de um romance; para detalhes ver: ELIAS, Norbert. Posfácio à edição Alemã - Outras facetas da relação estabelecidos-outsiders: o modelo Maycomb. In: Os estabelecidos e os outsiders. Rio de Janeiro : Zahar, 2000. Para detalhes sobre as relações entre nobreza e burguesia, ver: Estampa, 1987. A sociedade de corte. [S.1.] :
} 
equilíbrio instável de poder permite que o conceito de poder não seja utilizado como algo adquirido e então estático, assemelhando-se mais a um objeto do que uma espécie de força social. Assim, não é necessariamente do poder econômico ou da violência física que se está falando: o poder como algo estrutural das relações humanas pode caracterizar-se de diferentes maneiras de acordo com as relações que as pessoas realizam umas em direção às outras.

Então, como a perspectiva histórica, sociológica e processual, o equilíbrio de poder e a auto-imagem podem ser encontradas em uma relação estabelecidos-outsiders? Na obra cujo título é justamente "Os estabelecidos e os outsiders", Norbert ELIAS (2000) estuda uma comunidade industrial inglesa que se divide entre um grupo de moradores estabelecidos desde longa data e um grupo recente de moradores que eram tratados por aqueles como outsiders. $\mathrm{O}$ primeiro grupo levantava barreiras sobre o segundo, considerando-os como outsiders, estigmatizando-os e marginalizando-os. A auto-imagem dos moradores mais antigos possuía um caráter grupal distintivo que os colocava como melhores, possuidores de uma virtude humana superior. E esse grupo considerado superior tinha ainda a capacidade de fazer com que os indivíduos considerados inferiores se sentissem realmente sem virtudes, como seres humanos de qualidade inferior.

Os contatos entre eles eram apenas profissionais, pois muitos compartilhavam o mesmo espaço de trabalho nas fábricas da região. Os estabelecidos não mantinham nenhuma outra relação com "os de fora", acreditando que todos eram inferiores e que, de certa forma, poderiam ser "contaminados" com inferioridade. Havia uma forte vigilância e controle social que não deixavam que os contatos acontecessem, como por exemplo a fofoca depreciativa. Mas, na verdade, apenas uma pequena minoria dos novos residentes correspondia a imagem e a conduta de que falavam os antigos moradores. Daí uma linha geral das características que um grupo estabelecido realiza: a imagem atribuída aos outsiders é formada de acordo com a "minoria dos piores", a minoria anômica; já os estabelecidos constróem sua auto-imagem de acordo com sua parte mais nômica, na sua "minoria de melhores". Essas representações permitem ao grupo estabelecido afirmar a realidade do que é "ruim" do outro grupo e do que é "bom" do seu próprio grupo.

Antes de prosseguir é necessário saber como considera tanto o conceito de "anomia" como o de "estrutura social". É a partir de algumas considerações sobre esses conceitos em Merton e Durkheim ${ }^{3}$, que Elias mostra como ele próprio os utiliza.

\footnotetext{
${ }^{3}$ Émile Durkheim trabalhou avidamente para o estabelecimento da Sociologia como ciência. Sua obra abrange desde delimitações do campo de estudo da sociologia, conceitos e métodos, até estudos sobre educação. Considerado por muitos um dos pais fundadores da sociologia, o conceito de anomia é de suma importância em sua obra. Para detalhes sobre o conceito e formas diferentes
} Revilu, Yermicule 
Assim, analisa que para Merton a anomia e a estrutura social são dois pólos dissociados. Então, em uma dada situação, se existisse apenas a anomia não existiria estrutura social. Uma situação de anomia total corresponde à total falta de estrutura social, acontecendo então o caos cultural/social. Sendo assim, devido à falta de estrutura social, não há previsibilidade nem regularidade do comportamento social. Por outro lado, mostra que em Durkheim a anomia é considerada como um tipo particular de estrutura social, exemplificando com a sua análise do fenômeno do suicídio. Ou seja, ao prevalecer a anomia, esse tipo específico de estrutura social, os índices de suicídio são mais elevados. E nesse caso, entendendo melhor essa especificidade, a previsibilidade e a regularidade são mais acessíveis. (ELIAS, 2000, p. 190)

Com essas considerações, Elias mostra que a "estrutura social" de Merton tem uma conotação fortemente valorativa, considerada como a "boa sociedade/boa ordem/bem regulada"; e também valorativa é a "anomia", figurando como a "má sociedade/má ordem/má regulada". Na realidade, o que se apresenta são diferenças de estrutura social, como apontadas por Durkheim. Ou seja, ele já mostrava que diferentes estruturas sociais, sejam elas "bem reguladas" ou "mal reguladas", possuem regularidades sociais. Assim, o conceito de estrutura social "pode ser usado [tanto] como referência a grupos mais estreitamente integrados quanto a outros menos integrados." (ELIAS, 2000 , p. 191) Porém, o conceito de anomia também não é atribuído como um elemento constitutivo da sociedade da mesma forma: em Merton, a perspectiva é mais microssociológica que macrossociológica, como em Durkheim (BOUDON, R.; BOURRICAUD, F., 1993, p. 25); e Elias acaba utilizando-o das duas maneiras. Mas, de qualquer forma, caso não se verifiquem as diferenças estruturais e as causas dessas diferenças, considerando que a anomia também tem estrutura social, é o juízo de valor que irá decidir a análise da situação.

O conceito de anomia pretende traduzir de uma forma mais clara a noção vaga de desregramento social. Mas seu conteúdo varia bastante de um autor para outro. (cf. BOUDON, R. e BOURRICAUD, F., 1993, p. 27) Seguindo esse pensamento, varia também em Elias. Além das formas como utiliza, acrescenta à abordagem de Durkheim a sua concepção processual e de interdependência entre as diferentes estruturas sociais consideradas "ordem" e "desordem".

de sua utilização, ver: DURKHEIM, Émile. Da divisão do trabalho social. São Paulo : Martins Fontes, 1999. E também:

O suicídio. São Paulo: Martins Fontes, 1999. A teoria de Durkheim foi retomada e valorizada na produção da sociologia norte-americana, principalmente na década de 60. Robert K. Merton faz parte dessa corrente, geralmente rotulada como "funcionalista". Para um aprofundamento sobre o autor e a utilização que faz do conceito de anomia, ver: MERTON, R. K. Sociologia: teoria e estrutura. São Paulo : Mestre Jou, 1970. 
Pode-se continuar daqui, exemplificando então essa concepção processual. A coesão do grupo estabelecido baseava-se na coesão das famílias que se conheciam a duas ou três gerações. Já os recém-chegados não eram estranhos apenas para os antigos moradores como também entre eles devido ao fato de procederem de diferentes partes da Inglaterra, sendo na maioria refugiados de guerra. Ou seja, seus laços comunitários eram mais frouxos. Pode-se perceber que essa perspectiva sociológica está permeada de fatores e acontecimentos históricos que proporcionaram essa configuração, ou seja, esse processo de interdependência que os indivíduos formam entre si e que, da mesma forma processual, fornece-lhe a dinâmica, a continuidade $\mathrm{e}$ as possibilidades de mudança.

A única diferença entre os grupos, então, era o tempo de residência, a antigüidade de moradia no local. A antigüidade proporcionava maior coesão, identificação coletiva e as normas comuns a todos que participavam da superioridade e as usavam como desprezo aos outros grupos. Tal sentimento de superioridade gerava gratidão, ser melhor por pertencer a um grupo superior; sentimento complementado pelo desprezo pelos outros. (ELIAS, 2000, p. 2021).

Devido a maior coesão, os estabelecidos conseguiam reservar para as pessoas do seu grupo os cargos importantes das organizações locais (o clube, a escola, as organizações da Igreja), realizando avidamente a exclusão dos moradores recentes, da outra área de moradia. Aqui aparece a idéia de equilíbrio de poder citada anteriormente. Excluir e estigmatizar eram elementos que serviam para afirmar sua identidade e superioridade, mantendo os outros no lugar em que achavam que deveriam ficar. (ELIAS, 2000, p. 22) Essa relação da coesão com a posse de cargos importantes na comunidade, o que também reforça a coesão, é uma peça chave para entender o poder que os estabelecidos possuem e os meios que utilizam para manter seu equilíbrio, adquirindo um caráter de superioridade em relação aos outsiders.

Os recursos de poder que o grupo estabelecido possuía eram muito superiores em relação ao grupo outsider. Ou seja, o equilíbrio de poder, nesse caso, pendia muito mais para o grupo estabelecido que, assim, podiam levantar barreiras contra os outsiders excluindo-os e os marginalizando, o que servia também para manter o equilíbrio de poder. Mas isso não quer dizer que os outsiders, de forma geral, são destituídos de poder. Mesmo sendo grande o diferencial, caso o poder de um dos lados fosse nulo, não haveria interdependência.

Numa relação estabelecidos-outsiders, pode-se verificar a existência da interdependência entre os grupos já pelo sentido de que não é possível analisar as ações - sejam atuações, meios ou objetivos - de um grupo tomadas isoladamente como se fossem ações particulares desse grupo. Só o equilíbrio de 
poder, ou as forças de coerção presentes na estrutura de interdependência entre eles é que torna possível explicar o processo de suas ações. A dinâmica das figurações estabelecidos-outsiders só é compreendida tendo em vista a análise de processos a longo prazo, no caráter diacrônico do desenvolvimento dos grupos, levando em conta a interpenetração de seus objetivos e ações. "Termos como 'interpenetração' assinalam a natureza processual de tais relações." (ELIAS, 1999, p. 86) E assim, a auto-imagem que as pessoas ou grupos de pessoas fazem de si e dos outros está configurada pela percepção que realizam das suas relações em uma teia de interdependência. E nessa teia se processam a concepção do "nós" e dos "outros". Desse caráter processual entende-se que, na concepção sociológica de Elias, indivíduo e sociedade não são termos que se excluem, mas que as ações que os indivíduos realizam entre si, orientados para os outros e para si, são ações interdependentes que caracterizam uma configuração que só pode ser entendida no processo a longo prazo em que se constituiu e que está em constante movimento. A configuração é entendida como um "padrão mutável criado pelo conjunto dos [...] [indivíduos] não só pelos seus intelectos mas pelo que eles são no seu todo, a totalidade das suas ações nas relações que sustentam uns com os outros." (ELIAS : 1999, p.142)

Dentre as inúmeras formas que podem assumir uma relação estabelecidos e outsiders, pode-se tirar outra linha comum: os conflitos que se realizam, sejam explícitos ou sutis, são conflitos para modificar o equilíbrio do poder. Os outsiders pressionam de um lado para reduzir as diferenças de poder que os colocam como inferiores, já os estabelecidos pressionam para preservar essas diferenças e assim se preservarem. (ELIAS, 2000, p. 37) Um recurso usual dos establishments sob pressão é o reforço das pressões que os membros do seu próprio grupo impõem a si mesmos e ao grupo outsider. Fica claro que as diferenças de normas e padrões de autocontrole entre estabelecidos e outsiders assume um papel fundamental pois, para os estabelecidos, visualizar a não observação dessas normas pelos outros é desagradável e irritante pois elas estão ligadas a sua auto-imagem. E também porque a não observância dessas normas pelos outros significa o enfraquecimento do grupo pois pode tirar-lhes a sua própria defesa contra o rompimento de sua próprias normas. Mesmo aqueles outsiders que parecem ser mais flexíveis às normas dos estabelecidos, mesmo que procurem se "encaixar", são fortemente vistos pelos estabelecidos como uma ameaça à sua posição, à sua virtude e ao seu poder, pois precisam manter sua posição superior perante os outros. (ELIAS, 2000, p.49-50) Por exemplo, pode-se verificar que a interdependência que constitui uma configuração forma tensões específicas que podem se estabelecer como um processo de aliados e de adversários.

De forma geral, na obra de Elias prevalece um estudo de abordagem configuracional que caracteriza-se pelas conexões entre poder, comportamento, 
emoções e conhecimento em uma perspectiva a longo prazo, processual. Usualmente envolve uma ponte entre o macro e o micro e vice-versa, e não uma divisão entre eles, o que permanece incomum atualmente nas ciências sociais. Como apresentada na obra "Os estabelecidos e os outsiders", em vez de analisar uma comunidade através de categorias econômicas, históricas, religiosas, entre outras possíveis, tendo-as separadamente e depois fazendo relações, Elias faz um caminho oposto e analisa como essas categorias se apresentam vinculadas a uma comunidade. A questão é saber quais são "os aspectos comunitários específicos de uma comunidade?" (ELIAS, 2000, p. 165) Nesse caso, uma primeira resposta é que a comunidade evidencia-se pela rede de relações estabelecidas entre pessoas no seu cotidiano formando uma configuração específica de uma unidade residencial. São as relações que acontecem entre as pessoas que moram juntas em um mesmo lugar; as interdependências que se estabelecem são particularmente comunitárias. Mas as configurações tornam-se mais complexas na forma em que as teias de interdependências e configurações se intensificam. Então, em aplicações mais complexas e mais gerais, questões mais complexas e mais gerais podem aparecer, não esquecendo que os processos a longo prazo são imprescindíveis quando se quer tal compreensão.

Essa forma de estudo, um estudo de configurações, não deve privilegiar, de qualquer forma, o que se apresenta como "disfuncional". Procura sim explicar configurações interdependentes. Uma comunidade e seus moradores, os residentes do bairro mais antigo e os recém-chegados de um bairro relativamente mais novo, não apareceria na forma apresentada se não estivessem ligados um ao outro, e vice-versa, "[...] só puderam encaixar-se nos papéis de estabelecidos e outsiders por serem interdependentes." (ELIAS, 2000, p. 181) E dessa forma mostra que a investigação sociológica tem como ponto de partida os processos a longo prazo constituídos e vividos por uma pluralidade de indivíduos, que é a significação de dizer que eles existem em configurações e que de alguma forma são interdependentes. E irredutíveis são as configurações pois não se pode explicá-las existindo independentemente dos indivíduos e nem que os indivíduos existem independentemente delas. (ELIAS, 2000, p. 184)

Da perspectiva de Elias, desde a infância somos dependentes, de alguma forma e de várias formas, de inúmeros indivíduos. E somente analisando o processo de interdependência que forma um tipo de configuração entre os indivíduos é que podemos atingir uma reflexão científica mais adequada da vida social. Assim, a sociologia deve estar vinculada ao movimento e ao caráter processual das sociedades, da interdependência dos indivíduos e da interpenetração das suas ações e objetivos e, assim, verificar os elementos que as constituem, como a auto-imagem e a percepção dos "outros". 
Percebe-se então que a aproximação com a história é de grande importância. Esta não deve ser concebida simplesmente como uma seqüência de fatos desencadeados por um indivíduo ou um grupo de indivíduos que figuram das mais diferentes formas - revolucionários, políticos, classes sociais, homens, mulheres, etc. - mas sim dos processos a longo prazo nos quais vivem e participam, da interdependência que formam entre si, das configurações existentes em um dado momento e do movimento que realizam, da forma que expressam um sentido para sua auto-imagem e para a imagem dos outros e das lutas para mudar o equilíbrio de poder.

\footnotetext{
Dependemos dos outros; os outros dependem de nós. Na medida em que somos mais dependentes dos outros do que eles são de nós, em que somos mais dirigidos pelos outros do que eles são por nós, estes têm poder sobre nós, quer nos tenhamos tornado dependentes deles pela utilização que fizeram da força bruta ou pela necessidade que tínhamos de ser amados, pela necessidade de dinheiro, de cura, de estatuto, de uma carreira ou simplesmente de um estímulo. (ELIAS, 1999, p. 101)
}

Pode-se concluir percebendo a "dificuldade" que uma teoria como a de Norbert Elias tem para adentrar nas discussões da sociologia e outras disciplinas das ciências humanas. Mesmo que descoberta tardiamente, não se justifica considerar apenas esse fato para o escasso estudo da sua obra. É possível analisar tal "dificuldade" pela própria teoria das configurações de Elias. Ou seja, o conjunto de conceitos e categorias de análise que se concretizaram ao longo do tempo, os paradigmas que norteiam a comunidade científica, são geralmente tomados como únicos e verdadeiros. São os elementos utilizados para analisar a realidade. E são tão institucionalizados que, dependendo da forma como são utilizados, paradigmas, conceitos e realidade se confundem.

O conhecimento científico tradicional pode ser considerado um establishment que se defende atacando, criticando e até mesmo analisando do alto de sua posição superior, as outras formas de conhecimento. Qualquer forma de conhecimento que não participe de suas regras, normas e que ignore suas coerções acaba ficando no papel de outsider. Os membros da "boa comunidade científica" participam das vantagens e do sentimento de gratidão que ela proporciona: a carreira e os títulos, as publicações, a estabilidade, a recompensa financeira. ${ }^{4}$ Essa coesão, então, é permeada por normas rígidas que são continuamente reforçadas e somada ao desprezo pelos outsiders.

\footnotetext{
${ }^{4}$ Uma análise da lógica da comunidade científica em suas regras, das disputas pelo monopólio da competência científica, dos interesses e das recompensas que usufruem seus membros, pode ser encontrada em Pierre Bourdieu pelo que chama de "campo científico". Para detalhes, ver: BOURDIEU, Pierre. O campo científico. In: FERNANDES, Florestan (coord.) Pierre Bourdieu. Coleção Grandes Cientistas Sociais. Săo Paulo: Ática, 1995. p. 123-155.

66
}

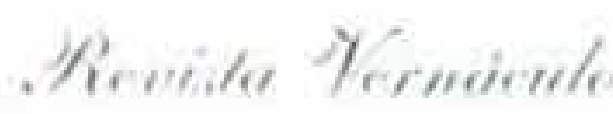


A especialização do conhecimento também tem uma configuração específica que procura se desfazer de uma interdependência científica ao mesmo tempo que olha para dentro de si e não enxerga sua interdependência interna. E por não ter conhecimento das forças que se processam nas configurações em que estão inseridas, ou por não querer enxerga-las, acabam por se isolar, cada uma das especialidades, a fim de se manterem longe do fantasma da sua possível extinção, de defender o seu conhecimento, o seu prestígio, o seu poder. E também para não se "contaminar" com o que acontece ao seu lado, pois isso fere sua identidade. Então, por fim, cada especialidade pode ser considerada um establishment no qual se realizam as regras e normatizações específicas e perante o qual a não observância desses processos caracteriza um "cientista de qualidade inferior".

A obra de Norbert Elias, de certa forma, acaba por não observar a tradição conceitual das ciências humanas, particularmente da sociologia, ferindo sua "auto-imagem" e colocando uma situação de "medo". E assim, criticar e apontar a ineficácia presente nessa tradição e, ao mesmo tempo, procurar introduzir um novo arcabouço teórico e metodológico que pretende ser capaz de compreender melhor os diferentes aspectos das sociedades humanas e seu caráter processual, faz com que muitas vezes ele não seja considerado, ou considerado pejorativamente, como "positivista" por exemplo, e nada mais que isso,

Como o próprio Elias coloca, os cientistas são destruidores de mitos, são um grupo que "geralmente criticam ou rejeitam as idéias dominantes aceitas pela maioria da sociedade em que vivem, mesmo quando são defendidas pela autoridade reconhecida, pois descobriram que não correspondem aos fatos observáveis." (ELIAS, 1999, p. 55) Resta aos próprios cientistas destruírem os mitos dos conceitos a priori, daqueles paradigmas que se institucionalizaram e tentam se agarrar de qualquer forma à realidade social. 


\section{Referências Bibliográficas}

BOUdON, R.; BOURRICAUd, F. Dicionário Crítico de Sociologia. São Paulo : Ática, 1993. p. 24-32.

BOURDIEU, Pierre. O campo científico. In: FERNANDES, Florestan (coord.) Pierre Bourdieu. Coleção Grandes Cientistas Sociais. São Paulo: Ática, 1995. p. 123-155.

DURKHEIM, Émile. Da divisão do trabalho social. São Paulo : Martins Fontes, 1999.

O suicídio. São Paulo: Martins Fontes, 1999.

ELIAS, Norbert. Introdução à sociologia. Lisboa : Edições 70, 1999.

Os estabelecidos e os outsiders. Rio de Janeiro : Jorge Zahar, 2000.

A sociedade de corte. [S.I.] : Estampa, 1987.

MERTON, R. K. Sociologia: teoria e estrutura. São Paulo : Mestre Jou, 1970. 